\title{
A characterization of major salivary gland flow rates in the presence of medications and systemic diseases
}

\author{
Ava J. Wu, DDS, ${ }^{a}$ and Jonathan A. Ship, DMD, ${ }^{b}$ Bethesda, Md. and Ann Arbor, Mich. \\ NATIONAL INSTITUTE OF DENTAL RESEARCH AND UNIVERSITY OF MICHIGAN, SCHOOL OF \\ DENTISTRY
}

\begin{abstract}
The purpose of this study was to characterize the effects of medications and systemic diseases on major salivary gland flow rates. Unstimulated and $2 \%$ citrate-stimulated parotid and submandibular salivas were collected from 293 subjects of the oral physiology component of the Baltimore Longitudinal Study of Aging. The influence of the number of medications and diseases on salivary flow rates was determined by separate one-way ANOVA tests. There was an overall decrease in both parotid and submandibular flow rates with increasing numbers of medications and systemic diseases. However, this was significant $(p<0.05)$ only for unstimulated submandibular flow rates (with increasing numbers of systemic diseases) and stimulated submandibular flow rates (with increasing numbers of systemic diseases and medications). Unstimulated flow rates rapidly approached zero with increasing numbers of medications and diseases. These results suggest that the submandibular gland may be more sensitive to physiologic permutations than the parotid gland. In adclition, individuals being treated for multiple systemic diseases and laking numerous medications may be more susceptible to salivary hypofunction. (OraL SURG ORAL Med ORal Pathol 1993;76:301-6)
\end{abstract}

Decreased salivation is a common side effect of drug use. ${ }^{1}$ An estimated 120 million people each year obtain prescription medications. ${ }^{2}$ Seventy-five percent of office visits to general medical practitioners and internists are associated with the continuation or initiation of a prescribed medication. ${ }^{3}$ The prevalence of xerostomia or the subjective complaint of dry mouth has been reported to be $29 \%$ in an adult population. ${ }^{4}$ However, many subjects in this study ${ }^{4}$ were taking medications, and this may have been the cause of their xerostomia. ${ }^{5}$ Indeed, several studies have associated medications with decreased salivary flow. ${ }^{6} 10$ Johnson et al. ${ }^{11}$ examined a population of chronically ill, longterm hospitalized elderly patients and found $44 \%$ of them complained of xerostomia and $43 \%$ actually had low stimulated parotid flow. These studies suggest that both medication use and systemic disease may influence salivary function.

Previous studies of medicated persons have examined only whole salivary or parotid flow rates. However, recent studies ${ }^{12-14}$ that examined parotid and submandibular/sublingual function separately suggest the submandibular/sublingual glands are more susceptible to the influence of systemic disease than the parotid gland. The purpose of this study was to

\footnotetext{
${ }^{a}$ Clinical Dental Staff Fellow, Clinical Investigations and Patient Care Branch, National Institute of Dental Research.

${ }^{b}$ Formerly, Senior Investigator, Clinical Investigations and Patient Care Branch, National Institute of Dental Research; currently, Associate Professor and Director, Hospital Dentistry, University of Michigan, School of Dentistry.

Copyright $\odot 1993$ by Mosby-Year Book, Inc. $0030-4220 / 93 / \$ 1.00+.107 / 13 / 48219$
}

characterize unstimulated and $2 \%$ citrate-stimulated parotid and submandibular/sublingual salivary flow rates in the presence of medications and systemic diseases in a well-characterized, ambulatory population.

\section{MATERIAL AND METHODS Study population}

The study population included 293 volunteer participants in the oral physiology component ${ }^{15}$ of the Baltimore Longitudinal Study of Aging. ${ }^{16}$ These persons were community-dwelling, ambulatory, white, and of middle socioeconomic class. Participants were examined by a physician, and diagnoses were based on clinical and laboratory results. ${ }^{17}$ Only subjects with well-controlled medical conditions were included in this study. Prescription medication usage was well documented in this population. Patients brought current medications to the clinic and completed a selfreported history that was reviewed by the examiner. Vitamins, aspirin, and topically applied dermatologic preparations were not included in the total medication count.

\section{Saliva collection}

Subjects refrained from eating, drinking, and oral hygiene procedures for a minimum of 90 minutes before salivary collection. Samples were collected between 8:30 AM and 11 AM by a single investigator (J.A.S.). Unstimulated (resting) samples were collected initially for 5 minutes. This was followed by stimulation with $2 \%$ citrate applied to the dorsolateral surfaces of the tongue for 5 seconds at 30 -second intervals. ${ }^{18}$ After a 2 -minute equilibration period, stim- 
Table I. Prevalence of high or low salivary gland flow rates according to the number of prescription medications*

\begin{tabular}{|c|c|c|c|c|c|c|c|c|c|}
\hline \multirow{2}{*}{$\begin{array}{l}\text { Number of } \\
\text { prescription } \\
\text { medicationst }\end{array}$} & \multirow{2}{*}{$\begin{array}{c}N \\
\text { Total }\end{array}$} & \multicolumn{2}{|c|}{$\begin{array}{l}\text { Unstimulated } t \\
\text { parotid }\end{array}$} & \multicolumn{2}{|c|}{$\begin{array}{l}\text { Stimulated } \\
\text { parotid }\end{array}$} & \multicolumn{2}{|c|}{$\begin{array}{l}\text { Unstimulated } \neq \\
\text { submandibular }\end{array}$} & \multicolumn{2}{|c|}{$\begin{array}{c}\text { Stimulated } \\
\text { submandibular }\end{array}$} \\
\hline & & Highई & Low & High & Low & High & Low & High & Low \\
\hline 0 & 171 & $\begin{array}{l}23 \\
(13) \mathbb{I}\end{array}$ & $\begin{array}{c}27 \\
(16)\end{array}$ & $\begin{array}{c}23 \\
(13)\end{array}$ & $\begin{array}{c}17 \\
(10)\end{array}$ & $\begin{array}{c}19 \\
(11)\end{array}$ & $\begin{array}{l}18 \\
(11)\end{array}$ & $\begin{array}{l}14 \\
(8)\end{array}$ & $\begin{array}{c}18 \\
(11)\end{array}$ \\
\hline 1 & 49 & $\begin{array}{c}8 \\
(16)\end{array}$ & $\begin{array}{c}12 \\
(24)\end{array}$ & $\begin{array}{c}8 \\
(16)\end{array}$ & $\begin{array}{c}5 \\
(16)\end{array}$ & $\begin{array}{c}4 \\
(8)\end{array}$ & $\begin{array}{c}17 \\
(35)\end{array}$ & $\begin{array}{c}1 \\
(2)\end{array}$ & $\begin{array}{c}12 \\
(25)\end{array}$ \\
\hline 2 & 43 & $\begin{array}{c}3 \\
(7)\end{array}$ & $\begin{array}{c}9 \\
(21)\end{array}$ & $\begin{array}{c}7 \\
(16)\end{array}$ & $\begin{array}{r}4 \\
(9)\end{array}$ & $\begin{array}{c}3 \\
(7)\end{array}$ & $\begin{array}{c}10 \\
(23)\end{array}$ & $\begin{array}{c}1 \\
(2)\end{array}$ & $\begin{array}{c}7 \\
(16)\end{array}$ \\
\hline 3 & 21 & $\begin{array}{c}1 \\
(5)\end{array}$ & $\begin{array}{c}6 \\
(28)\end{array}$ & $\begin{array}{c}3 \\
(14)\end{array}$ & $\begin{array}{c}5 \\
(24)\end{array}$ & $\begin{array}{c}0 \\
(0)\end{array}$ & $\begin{array}{c}7 \\
(33)\end{array}$ & $\begin{array}{c}0 \\
(0)\end{array}$ & $\begin{array}{c}7 \\
(16)\end{array}$ \\
\hline 4 & 7 & $\begin{array}{c}0 \\
(0)\end{array}$ & $\begin{array}{c}2 \\
(29)\end{array}$ & $\begin{array}{c}0 \\
(0)\end{array}$ & $\begin{array}{c}1 \\
(14)\end{array}$ & $\begin{array}{c}0 \\
(0)\end{array}$ & $\begin{array}{c}2 \\
(29)\end{array}$ & $\begin{array}{c}0 \\
(0)\end{array}$ & $\begin{array}{c}2 \\
(29)\end{array}$ \\
\hline 7 & 2 & $\begin{array}{c}0 \\
(0)\end{array}$ & $\begin{array}{c}2 \\
(100)\end{array}$ & $\begin{array}{c}0 \\
(0)\end{array}$ & $\begin{array}{c}0 \\
(0)\end{array}$ & $\begin{array}{c}0 \\
(0)\end{array}$ & $\begin{array}{c}1 \\
(50)\end{array}$ & $\begin{array}{c}0 \\
(0)\end{array}$ & $\begin{array}{c}1 \\
(50)\end{array}$ \\
\hline
\end{tabular}

*Based on lowest and highest 10 th percentile values from a control population. ${ }^{23}$

$\uparrow$ Total number of medications taken. Note that there is no one taking 5 or 6 medications.

$\Varangle$ Persons taking one or more medications are more likely to have a low (versus high) flow rate; chi-square, $p<0.05$.

$\$$ High salivary flow as determined from the highest 10th percentile of a control population.

ULow salivary flow as determined from the lowest 10 th percentile of a control population.

IO is the percentage of persons with a low or high salivary flow rate.

ulated parotid secretions were collected for 2 minutes. Unstimulated and stimulated parotid saliva was collected from a single salivary gland with the use of a modified Carison-Crittenden cup as described previously. ${ }^{19,20}$ Submandibular/sublingual saliva was collected from the orifice of Wharton's duct with a micropipette attached to gentle suction as described previously. ${ }^{21}$ After collection, the volume of saliva was determined gravimetrically, assuming a specific gravity of 1.0. Submandibular saliva, as defined in this article, represents a combined submandibular and sublingual secretion because of the frequent common exit of the gland ducts. ${ }^{22}$

\section{Statistical analysis}

Subjects were categorized according to the number of prescription medications that they were taking and the number of diseases for which they were currently being treated. The influence of the number of medications and the number of systemic diseases on each of the four major salivary flow rates was determined by one-way ANOVA tests. In addition, individual salivary gland flow rates were identified as being either low or high from previously established control population standards using the lowest or highest 10 th percentiles. ${ }^{23}$ The frequency of subjects with low or high salivary gland flow rates for each of the four flow rates was analyzed by a $\chi^{2}$ test. Data were analyzed with the use of RS1 software (BBN software products, Cambridge, Mass.). Significance was selected at the $p<0.05$ level.

\section{RESULTS}

Men $(N=169)$ and women $(N=124)$ between the ages of 19 to 93 years (mean age $=60.4$ years, median age $=64$ years) comprised the study population. One hundred seventy-one persons were taking no prescription medications, and 122 persons were taking one or more medications (Table I). One hundred eighty-two persons were not being treated for any mcdical discasc, and 111 persons werc bcing treated for one or more diseases (Table II). Unstimulated and stimulated major gland flow rates of unmedicated persons who were not being treated for any systemic diseases were not statistically different between men and women. Therefore the gender values were combined for all analyses.

Unstimulated and stimulated major salivary gland flow rates progressively diminish with increasing numbers of prescription medications (Fig. 1). However, this pattern was statistically significant only for stimulated submandibular flow rates for 0 to 7 medications ( $p=0.002$, Fig. 1) and from 0 to 4 medications $(p=0.001$, Fig. 1$)$. The distribution of subjects with salivary flow rates categorized as being either low or high according to the number of prescription medications is provided in Table I. With increasing numbers of drugs, the prevalence of subjects with low flow rates, according to control populations standards, ${ }^{23}$ increased. Conversely, the prevalence of subjects with high flow rates diminished with increasing numbers of drugs. Chi-square tests were performed between subjects who take no medications and per- 
Table Il. Prevalence of high or low salivary gland flow rates according to the number of systemic diseases*

\begin{tabular}{|c|c|c|c|c|c|c|c|c|c|}
\hline \multirow{2}{*}{$\begin{array}{l}\text { Number of } \\
\text { medical } \\
\text { conditions }\end{array}$} & \multirow{2}{*}{$\begin{array}{c}N \\
\text { Total }\end{array}$} & \multicolumn{2}{|c|}{$\begin{array}{l}\text { Unstimulatedf } \\
\text { parotid }\end{array}$} & \multicolumn{2}{|c|}{$\begin{array}{l}\text { Stimulated } \\
\text { parotid }\end{array}$} & \multicolumn{2}{|c|}{$\begin{array}{l}\text { Unstimulated }+ \\
\text { submandibular }\end{array}$} & \multicolumn{2}{|c|}{$\begin{array}{l}\text { Stimulated } f \\
\text { submandibular }\end{array}$} \\
\hline & & $H i g h t+$ & Low & High & Low & High & Low & High & Low \\
\hline 0 & 182 & $\begin{array}{c}24 \\
(13) \|\end{array}$ & $\begin{array}{c}28 \\
(15)\end{array}$ & $\begin{array}{c}27 \\
(15)\end{array}$ & $\begin{array}{l}16 \\
(9)\end{array}$ & $\begin{array}{c}19 \\
(10)\end{array}$ & $\begin{array}{c}21 \\
(12)\end{array}$ & $\begin{array}{l}14 \\
(8)\end{array}$ & $\begin{array}{l}16 \\
(9)\end{array}$ \\
\hline 1 & 71 & $\begin{array}{c}7 \\
(11)\end{array}$ & $\begin{array}{c}18 \\
(25)\end{array}$ & $\begin{array}{c}11 \\
(16)\end{array}$ & $\begin{array}{c}10 \\
(14)\end{array}$ & $\begin{array}{c}5 \\
(13)\end{array}$ & $\begin{array}{c}23 \\
(32)\end{array}$ & $\begin{array}{c}2 \\
(3)\end{array}$ & $\begin{array}{c}19 \\
(27)\end{array}$ \\
\hline 2 & 31 & $\begin{array}{r}3 \\
(10)\end{array}$ & $\begin{array}{c}8 \\
(26)\end{array}$ & $\begin{array}{c}3 \\
(10)\end{array}$ & $\begin{array}{c}2 \\
(6)\end{array}$ & $\begin{array}{c}2 \\
(6)\end{array}$ & $\begin{array}{c}8 \\
(26)\end{array}$ & $\begin{array}{c}0 \\
(0)\end{array}$ & $\begin{array}{c}8 \\
(26)\end{array}$ \\
\hline 3 & 8 & $\begin{array}{c}1 \\
\text { (13) }\end{array}$ & $\begin{array}{c}3 \\
(38)\end{array}$ & $\begin{array}{c}0 \\
(0)\end{array}$ & $\begin{array}{c}4 \\
(50)\end{array}$ & $\begin{array}{c}0 \\
(0)\end{array}$ & $\begin{array}{c}2 \\
(25)\end{array}$ & $\begin{array}{c}0 \\
(0)\end{array}$ & $\begin{array}{c}3 \\
(37)\end{array}$ \\
\hline 4 & 1 & $\begin{array}{c}0 \\
(0)\end{array}$ & $\begin{array}{c}1 \\
(100)\end{array}$ & $\begin{array}{c}0 \\
(0)\end{array}$ & $\begin{array}{c}0 \\
(0)\end{array}$ & $\begin{array}{c}0 \\
(0)\end{array}$ & $\begin{array}{c}1 \\
(100)\end{array}$ & $\begin{array}{c}0 \\
(0)\end{array}$ & $\begin{array}{c}1 \\
(100)\end{array}$ \\
\hline
\end{tabular}

*Based on lowest and highest 10 th percentile values from a control population. ${ }^{23}$

$\uparrow$ Persons being treated for one or more systemic diseases are more likely to have a low (versus high) flow rate; chi-square, $p<0.05$.

High salivary flow rate as determined from the highest 10th percentile of a control population.

\&ow salivary flow rate as determined from the lowest 10th percentile of a control population.

$\|()_{)}$is the percentage of persons with a low or high salivary flow rate.

sons who take one or more medications. Subjects who take one or more medications were significantly more likely to have low unstimulated parotid $(p=0.047)$, unstimulated submandibular $(p=0.001)$, and stimulated submandibular $(p=0.002)$ flow rates. For example, approximately one quarter or more of these persons had low unstimulated parotid and unstimulated and stimulated submandibular salivary flow rates compared with approximately $10 \%$ of subjects not taking any prescription medications (Table I).

According to Fig. 2, major salivary gland flow rates decline with increasing numbers of diseases. This was statistically significant for unstimulated submandibular $(p=0.04)$ and stimulated submandibular $(p=$ 0.001 ) flow rates for 0 to 4 diseases and from 0 to 3 diseases ( $p=0.03$ and $p=0.001$, respectively) but not for the parotid secretions. The distribution of subjects with salivary flow rates categorized as being either low or high according to the number of diseases for which subjects were being treated is provided in Table II. With increasing numbers of diseases, the prevalence of subjects with high flow rates decreased and the prevalence of subjects with low flow rates increased. Chi-square tests between persons being treated for one or more systemic diseases versus no diseases revealed that subjects with one or more systemic diseases were statistically more likely to have low unstimulated parotid $(p=0.015)$, unstimulated submandibular $(p=0.001)$, and stimulated submandibular $(p=0.001)$ flow rates. More than one quarter of the persons with one or more systemic diseases had low unstimulated parotid and unstimulated and stimulated submandibular flow rates, compared with approximately $10 \%$ of subjects not being treated for any systemic diseases (Table II).

\section{DISCUSSION}

This study examined individual parotid and submandibular salivary gland flow rates in a population of community-dwelling, volunteer participants taking prescription medications and having well-controlled systemic disease. The results of this study suggest that although there is a generalized decrease in parotid and submandibular flow rates in the presence of medications and systemic diseases, the submandibular gland is affected to a greater extent then the parotid gland. These conclusions extend previous findings that demonstrated a trend of decreasing whole salivary and parotid flow rates in the presence of diseases and medications in elderly institutionalized populations. ${ }^{1,9-11,24}$

Subjects taking one or more medications or being treated for one or more systemic diseases were not at greater risk of having low stimulated parotid flow rates compared with their healthy counterparts (Tables I and II). In contrast, subjects taking one or more medications or being treated for one or more diseases were more likely to have a low unstimulated and stimulated submandibular salivary flow rate (Tables I and II). Only the submandibular flow rates demonstrated a statistically significant decline in the presence of increasing medications and systemic diseases. One caveat to this observation is that the number of persons who take several medications or have numerous systemic diseases in this study is small. However, three studies that examined major salivary flow rates 
UNSTIMULATED FLOW

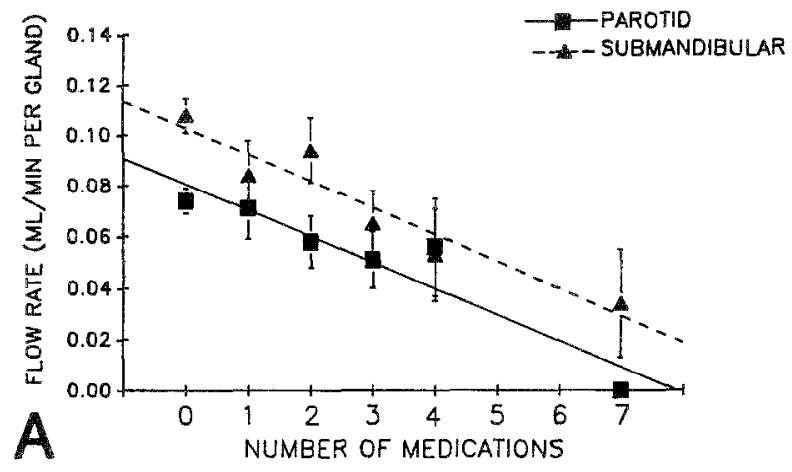

STIMULATED FLOW

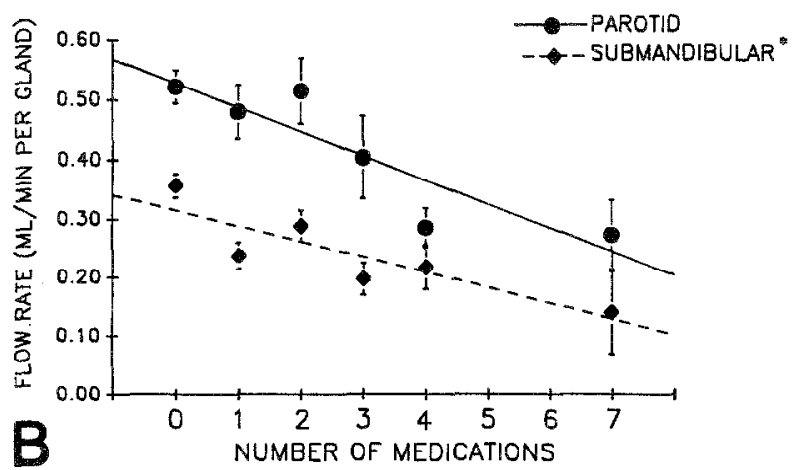

Fig. 1. Regression of mean ( \pm sem) (A) unstimulated and (B) 2\% citrate-stimulated parotid and submandibular flow rates according to prescription medications that subjects were taking. Total number of persons taking $0,1,2,3,4$, and 7 medications was $171,49,43,21,7$, and 2 respectively, One-way ANOVA results were statistically significant for stimulated submandibular flow rates $(p=0.002)$. Statistically significant results are denoted with an *.

of persons with one specific disease also found that the submandibular gland is more susceptible to the effects of systemic disease. ${ }^{12-14}$ Two percent citrate-stimulated submandibular flow rates were observed to be below normal in $87.5 \%$ of patients with Sjögren's syndrome while stimulated parotid flow was decreased in only $54.7 \% .{ }^{12}$ In unmedicated patients with Alzheimer's disease, unstimulated and stimulated submandibular gland flow rates were markedly diminished with no alteration in parotid secretions. ${ }^{13} \mathrm{~A}$ longitudinal evaluation of major salivary gland function in HIV-1 infected patients found that the submandibular gland manifested alterations in function earlier than the parotid gland. ${ }^{14}$ Therefore the findings in this study corroborate studies that examined the effect of a specific disease on salivary flow suggesting that the submandibular gland may be preferentially vulnerable to exogenous influences.

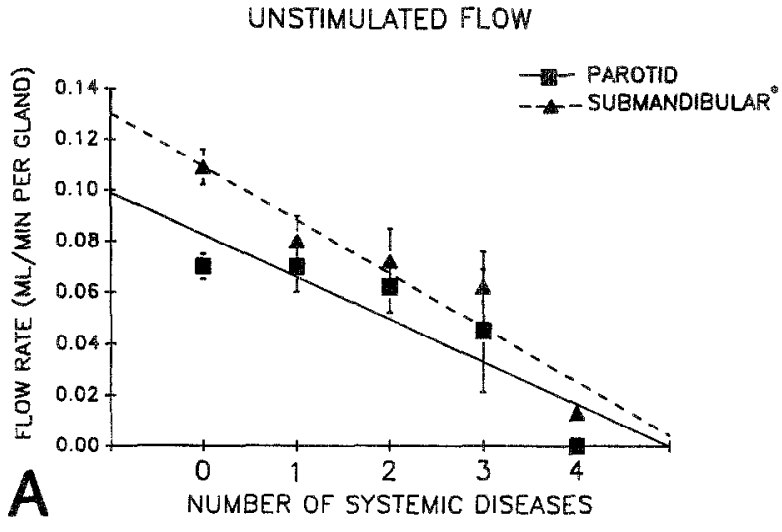

STIMULATED FLOW

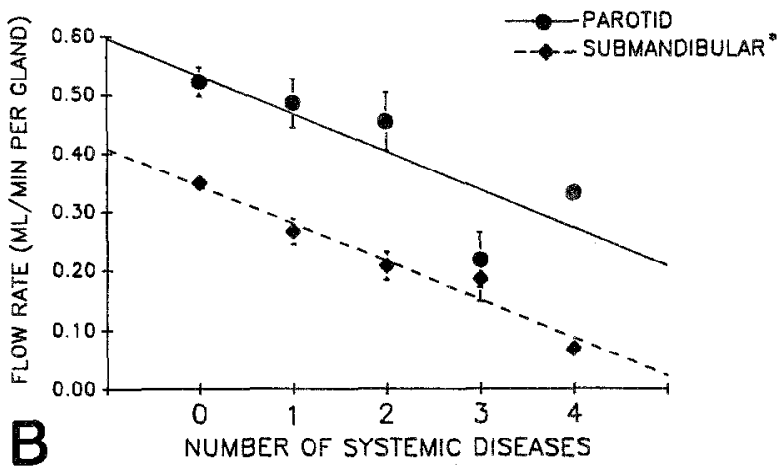

Fig. 2. Regression of mean ( \pm sem) (A) unstimulated and (B) $2 \%$ citrate-stimulated parotid and submandibular flow rates according to systemic diseases that subjects were being treated for. Total number of persons with $0,1,2,3$, and 4 systemic diseases was $182,71,31,8$, and 1 respectively. One-way ANOVA results were statistically significant for unstimulated submandibular $(p=0.04)$ and stimulated submandibular flow rates $(p=0.001)$. Statistically significant results are denoted with an .

The significance of this finding is that the submandibular gland is a major contributor to total salivary production. The proportional contribution of the submandibular, parotid, and sublingual glands under resting or unstimulated conditions has been estimated to be $69 \%, 26 \%$, and $5 \%$, respectively. ${ }^{25}$ The contribution of the minor glands has been determined to be from 0 to $8 \%$. ${ }^{25,26}$ This article considers submandibular and sublingual secretions as a single measurement. Therefore in the most severe case of total loss of unstimulated submandibular/sublingual flow, a person may lose up to $74 \%$ of their total unstimulated salivary production.

Many histologic, anatomic, neurologic, and physiologic differences exist between the submandibular and parotid gland in health, in aging, and in the presence of systemic diseases. ${ }^{27}$ To date there is no suitable explanation for this apparent increased suscepti- 
bility of the submandibular gland secretory function to medication and disease. Collection of whole or parotid saliva is limited in that it does not provide comprehensive functional information about all major glands. This study demonstrates the need for more information regarding the submandibular gland.

Unstimulated salivary flow rates rapidly approached zero with increasing numbers of medications and diseases (Figs. 1 and 2) In addition, those persons taking one or more medications or having one or more diseases were more likely to have unstimulated parotid and unstimulated submandibular flow rates that were in the lowest 10th percentile than in the highest 10th percentile of salivary flow rates (Tables I and II) This is an important observation because unstimulated salivary flow is a measure of the amount of saliva that is constantly secreted to protect and to lubricate the oral cavity, whereas stimulated salivary flow is a measure of the functional capacity of the gland. Unstimulated secretions may be of greater significance to person's perception of dryness as well as their ability to maintain homeostasis. ${ }^{5}$ Therefore the results from these analyses exhibit a pattern suggesting that persons being treated for numerous systemic diseases and/or taking multiple medications are likely to have little or no unstimulated salivary output. As a result, these persons are not receiving the full protection provided by saliva and are placed at increased risk for developing the numerous complications of salivary gland hypofunction. ${ }^{2.8}$

A limitation of this study is that it was not possible to truly separate the effects of medications and diseases on salivary flow. Many subjects had a systemic disease and were taking one or more prescription medications. Therefore it is unknown if the salivary effects seen in this study are due to the effects of medication, the effects of diseases, or a combination of both. Unfortunately, it was not possible to distinguish effects of individual medications or systemic diseases on major salivary gland flow rates because of the small sample size of persons in these groups.

In this study, age and gender were not considered factors that would significantly influence major salivary gland flow rates. Major salivary gland flow rates appear to be gender independent, $18,20,27,29$ and parotid salivary flow rates remain stable with age in healthy persons..$^{20,29,30}$ However, the effect of healthy aging on submandibular function is not as clear-cut. Pederson et al ${ }^{31}$ found an age-associated decrease in submandibular flow rates. Alternatively, Tylenda et al., ${ }^{18}$ with the use of salivary collection techniques similar to those used in this study, found no changes in submandibular gland flow rates across the human life span.
The results of this study demonstrate that with increasing numbers of diseases and medications, there is a greater likelihood that major salivary gland output will decrease. Unstimulated salivary flow rates rapidly approach zero in the presence of increasing medications and diseases. In addition, the submandibular gland may be more susceptible to external or physiologic permutations than the parotid gland. This study utilized only subjects taking prescription medications who had well-controlled disease. One may speculate that subjects who take multiple medications with uncontrolled disease may exhibit even greater salivary dysfunction. It will be necessary in future investigations to define which and how specific drugs and diseases have a deleterious effect on salivary gland function as well as the effect of the interaction of numerous medications and medical conditions on secretory function. Ultimately, it will be necessary to completely understand and diagnose salivary dysfunction so as to direct studies aimed at the treatment of xerostomia.

We thank Dr. Bruce Baum (CIPCB, NIDR, NIH) for continuing research guidance and Drs. Jane C. Atkinson (CIPCB, NIDR, NIH) and Charles F. Streckfus (EODPP, NIDR, NIH) for critical review of the manuscript.

\section{REFERENCES}

1. Handelman SL, Baric JM, Saunders RH, Espeland MA. Hyposalivatory drug use, whole stimulated salivary flow, and mouth dryness in older, loug-term care residents. Spec Care Dent 1989;9:12-18.

2. Kasper JA. Prescribed medicines: use, expenditures, and sources of payment. National Health Care Expenditures Study Data Preview 9. Department of Health and Human Services publication (PHS) 82-3320. Public Health Service. Hyattsville, Maryland: National Center for Health Services Research, 1982.

3. Cypress BW. Drug utilization in office visits to primary care physicians: national ambulatory medical care survey, 1980 Department of Health and Human Services publication (PHS) 32-1250. Public Health Service, 1982.

4. Sreebny LM, Valdini A. Xerostomia. Part I; relationship to other oral symptoms and salivary gland hypofunction. ORAL Surg Oral Med Oral Pathol 1988;66:451-8.

5. Sreebny LM, Valdini A, Yu A. Xerostomia. Part II: relationship to nonoral symptoms, drugs, and diseases. ORaL Surg Oral Med Oral Patilol 1989;68:419-27.

6. Parvinen T, Parvinen I, Larmas M. Stimulated salivary flow rate, $\mathrm{pH}$ and lactobacillus and yeast concentrations in medicated persons. Scand J Dent Res 1984,92:524-32.

7. Scopp I, Heyman R, Goldberg M, Croy D. Dryness of the mouth with use of tranquilizers: chlorpromazine. J Am Dent Assoc 1965;71:66-9.

8. Rafálson OJ, Clemmesen L, Lund $\mathrm{H}$, Mikkelsen PL, Bolwig TG. Comparison of peripheral anti-cholinergic effects of antidepressants: drymouth. Acta Psychiatr Scand 1981;290:364-9.

9. Persson RE, Izutsu KT, Truelove EL, Persson R. Differences in salivary flow rates in elderly subjects using xerostomic medications. Oral Surg Oral MEd Oral Pathol 1991;72:42-6.

10. Thorselius I, Emilson CG, Österberg T. Salivary conditions and drug consumption in older age groups of elderly Swedish individuals. Gerodontics 1988;4:66-70. 
11. Johnson $G$, Barenthin I, Westphal, P. Mouth dryness among patients in long-term hospitals. Gerodontology 1984;3:197203.

12. Atkinson JC, Travis WD, Pillemer SR, Bermudez D, Wolff A, Fox PC. Major salivary gland function in primary Sjögren's syndrome and its relationship to clinical features. J Rheumatol 1990;17:318-22.

13. Ship JA, DeCarli C, Friedland RP, Baum BJ. Diminished submandibular salivary flow in dementia of the Alzheimer type. J Gerontol 1990;45:M61-6.

14. Atkinson JC, Yeh CK, Bermudez D, Fox PC, Baum BJ. Longitudinal evaluation of major salivary gland function in HIV-1 infected patients. J Oral Pathol Med 1989;18:469-70.

15. Baum BJ. Characteristics of participants in the oral physiology component of the Baltimore longitudinal study of aging. Comm Dent Oral Epidemiol 1981;9:128-34.

16. Shock NW, Greulich RC, Andres R, et al. Normal human aging: the Baltimore longitudinal study of aging, NIH Publication No. 84-2450. Washington, DC: U.S. Government Printing Office, 1984.

17. Metter EJ, Walega D, Metter EL, et al. How comparable are healthy 60- and 80-year-old men? J Gerontol 1992;47:M73-8.

18. Tylenda CA. Ship JA, Fox PC, Baum BJ. Evaluation of submandibular salivary flow rate in different age groups. J Dent Res 1988;67:1225-8.

19. Baum BJ. Evaluation of stimulated parotid flow rate in different age groups. J Dent Res 1981;60:1292-6.

20. Heft MW, Baum BJ. Unstimulated and stimulated parotid salivary flow rate in individuals of different ages. $J$ Dent Res 1985;63:1182-6.

21. Fox PC, van der Ven PF, Sonies BS, Weiffenbach JM, Baum BJ. Xerostomia: evaluation of a symptom with increasing significance. J Am Dent Assoc 1985;110:519-25.

22. Hand AR. Salivary glands. In: Bhaskar SN, ed., Orban's oral histology and embryology, 11th ed, St. Louis: Mosby-yearbook, 1991:357.

23. Ship JA, Fox PC, Baum BJ. How much saliva is enough? normal function defined. J Am Dent Assoc 1991;122:63-9.

24. Saunders RH, Handelman SL. Effects of hyposalivatory medications on saliva flow rates and dental caries in adults aged 65 and older. Spec Care Dent 1992;12:116-21.

25. Schneyer LM. Source of resting total mixed saliva of man. $J$ Appl Physiol 1956;9:79.81.

26. Dawes $\mathrm{C}$, Wood CM. The contribution of oral minor mucous gland secretions to the volume of whole saliva in man. Arch Oral Biol 1973;18:337-42.

27. Baum BJ, Ship JA, Wu AJ. Salivary gland function and aging: a urodel for studying the interaction of aging and systemic disease. Crit Rev Oral Biol Med 1992;4:53-64.

28. Mandel ID. The role of saliva in maintaining oral homeostasis. J Am Dent Assoc 1989:19:298-304.

29. Ship JA, Baum BJ. Is reduced salivary flow normal in old people? Lancet 1990;336:1507.

30. Chauncey HH, Borkan G, Wayler AW, Feller RP, Kapur KK. Parotid fiuid composition in healthy aging males. Adv Physiol Sci 1981;28:323-8.

31. Pederson W, Schubert M, Izutsu K, Mersai T, Truelove E. Age-dependent decreases in human submandibular gland flow rates as measured under resting and poststimulation conditions. J Dent Res 1985;64:822-5.

Reprint requests:

Ava J. Wu, DDS

$\mathrm{NIH} / \mathrm{NIDR} / \mathrm{CIPCB}$

Building 10, Room 1N-113

9000 Rockville Pike

Bethesda, MD 20892 